\section{Functional Capacity Evaluations}

Tamara Bushnik

Director of Inter-Hospital Research and Knowledge Translation, Rusk Rehabilitation, New York, NY, USA

\section{Synonyms}

FCEs

\section{Definition}

The measurement of capacity as it pertains to demands that are specific to a job and/or task. FCEs traditionally evaluate the match between the individual's abilities and/or limitations and the functional ability required to adequately address the needs of the job/workplace. An individual's abilities and/or limitations includes, not only consideration of anthropometrics, biomechanics, and cardiopulmonary factors, but also perceptual and cognitive abilities that are required to accomplish the job and/or task. The most common uses of FCEs are following an injury (not necessarily at the workplace) when an individual needs to be assessed for return to work possibilities, work accommodations, and/or the need for rehabilitation services. Factors influencing the validity of an FCE include involvement in legal action, lack of standardized tools, and the difficulty in assessing motivation and effort expended by the individual being assessed.

\section{References and Reading}

Gross, D. P., \& Battie, M. C. (2005). Functional capacity evaluation performance does not predict sustained return to work in claimants with chronic back pain. Journal of Occupational Rehabilitation, 15, 285-294.

Gross, D. P., \& Battie, M. C. (2006). Does functional capacity evaluation predict recovery in workers' compensation claimants with upper extremity disorders? Occupational and Environmental Medicine, 63, 404-410.

Mahmud, N., Schonstein, E., Schaafsma, F., Lehtola, M. M., Fassier, J. B., Verbeek, J. H., \& Reneman, M. F. (2010). Functional capacity evaluations for the prevention of occupational re-injuries in injured workers. Cochrane Database Systematic Reviews, (7), CD007290.

Pransky, G. S., \& Dempsey, P. G. (2004). Practical aspects of functional capacity evaluations. Journal of Occupational Rehabilitation, 14, 217-229. 